\title{
A Comparative Analysis of Conflict Management Styles between Local and Expatriate Managers in Hong Kong-Based Multinational Corporations
}

\author{
Li-Ying Wu, Bertha Du-Babcock
}

Wenzao Ursuline University of Languages, Kaohsiung, Taiwan, Republic of China

Objectives: This paper investigates and compares how and whether conflicts are managed differently between expatriate managers and Hong Kong local managers when handling conflicts with organizational members from different organizational levels.

Methods: Both quantitative and qualitative data were collected. To examine the differences, Rahim's ROCI-II Forms A, B, and C questionnaires were administered to 41 expatriate and 50 local managers working at multinational corporations in Hong Kong. The questionnaire addresses five conflict management styles (CMS). In total, 273 questionnaires were collected. Ninety-one in-depth interviews were also conducted to strengthen findings and interpretation of the questionnaire data.

Results: The findings show that similar and different preferred CMS are observed in both expatriate and local managers when handling conflicts at different organizational levels; to superiors, subordinates, and peers. Of five CMS, integrating style was the most preferred CMS by both expatriate and local managers. Dominating style was preferred when handling conflicts with subordinates by expatriate and local managers, while compromising style was likely to be used by local managers but not expatriate managers. Avoiding style, being considered lose-lose orientation, is least preferred. By adopting the avoiding style, both parties tend to withdraw themselves from the conflict scenes and leave conflicts go unaddressed.

Conclusions: Findings suggest that culture affects the use of CMS between expatriate and local managers. Differences also are found by local and expatriate managers when dealing with conflicts in different organizational levels. We also provide implications, limitations, and suggestions for future research.

Key Words: Conflict Management Styles, Collectivist, Individualist, Conflict Resolution, Cross-Cultural Comparison

Received: Sep 7, 2020 Revised: Nov 3, 2020 Accepted: Dec 9, 2020

Corresponding author: Bertha Du-Babcock

900 Mintsu $1^{\text {st }}$ Road, Kaohsiung 80793, Department of English, Wenzao Ursuline University of Languages, Kaohsiung, Taiwan, Republic of China Tel: +886-7-342-6031 (ext: 5361), E-mail: enbertha@gmail.com

This is an Open Access article distributed under the terms of the Creative Commons Attribution Non-Commercial License (http://creativecommons.org/licenses/ by-nc/4.0/) which permits unrestricted non-commercial use, distribution, and reproduction in any medium, provided the original work is properly cited.

Copyright $\odot 2021$ Korean Association for Business Communication.

\section{Introduction}

Intercultural contact has created an environment for potential communication conflict among individuals speaking different languages and coming from diverse cultures. Managing conflicts represents an important managerial duty. Past research (e.g., Thomas \& Schmidt, 1976) has shown that managers can spend as much as $20 \%$ of their time resolving conflicts. Due to the increasing globalization of the world economy, the amount of time spent on managing conflicts may increase (Aguinis \& Kraiger, 1996; Morris et al., 1998; Smith \& Bond, 1993). A re- 
cent survey has suggested that managers can spend as much as $40 \%$ of their time resolving employee conflicts at the workplace (Desikan, 2018). Consequently, the importance of understanding cross-cultural differences in conflict management behavior has grown.

The trends of the global economy and Hong Kong's efforts to become a regional hub of international financial centers have attracted many multinational corporations (MNCs) and expatriate managers working in Hong Kong. Due to cultural and managerial style differences, these expatriate managers and their Hong Kong local colleagues have encountered various conflicts; some are common to all organizations and others are unique. How these managers resolve conflicts in such a multilingual and multi-cultural setting in Hong Kong is practically and theoretically significant.

Gudykunst (1994) noted that cultural differences affect how people attribute and categorize conflicts. Consequently, people from different cultures manage conflicts differently. The two major factors that influence conflict management or resolution arise from cultural context and language differences (Chen \& Starosta, 1998). Cultural values (Hall, 1976; Hofstede, 1980) have been proposed as one reason for differences in behavioral styles in conflict situations. Hofstede's (1980) four dimensions of cultural values, especially Individualism-Collectivism (IC), have been widely applied as a theoretical framework for conflict management studies from a cross-cultural perspective (Ting-Toomey, 1988; Trubisky, Ting-Toomey, \& Lin, 1991).

Past research examining effects of culture on conflict management styles (CMS) have not been consistent and conclusive. Leung's (1988) study correlated participant's conflict management scores with I-C scale found no relationship between these two variables. He argued that although theorists have suggested that Asian managers are more disposed to an avoidance style than Western managers, the Asian ingroup-outgroup differences may also have influenced the way of dealing with conflict avoidance between ingroup and outgroup members. Morris et al. (1998) argued that studies have repeatedly shown that the precise cultural boundaries on CMS differences are not well understood and proposed that the measures of I-C account hold separate U.S. managers from Asian managers.

Language or communication styles (Hall, 1976) embedded in the cultural context also may affect conflict management. Studies by Ting-Toomey $(1985,1988)$ theorized the differences in conflict management or resolution between low-and high-context cultural societies. Her studies reveal that individuals from high-context cultural societies tend to adopt non-confrontational and indirect approaches to smooth over conflicts; whereas, individuals from low-context cultural societies tend to become involved in a conflict and adopt a confrontational and direct approach in managing conflicts.

The present study uses Rahim's model of conflict management to examine the differences in CMS between expatriate managers and Hong Kong local managers. The cultural dimension of I-C (Hofstede, 1985, 1991) and low-context-high context (Hall, 1976) are also adopted to provide the cultural context for the study. Rahim's (2001) conceptualization of the CMS is used in the current study not only because of its validity (Weider-Hatfield, 1988), but also because of its compatibility with the dimension of I-C (Ting-Toomey et al., 2000). Subsequently, the current study attempts to answer the following research questions (RQs):

RQ1: Do Hong Kong local and expatriate managers exhibit similar or different CMS?

RQ2: Do Hong Kong local and expatriate managers exhibit similar or different CMS when managing conflicts at different organizational levels; to superiors, to subordinates, and to peers?

\section{Literature Review}

This section reviews the relevant constructs and variables as well as their interactions involving: (1) individualism - collectivism cultural construct and (2) typologies of conflict handling styles.

Individualism-Collectivism and Conflict Management Styles Cultural theorists have given several explanations to attribute cultural differences on CMS. Employees of individualist societies have low sacrifice, high self-reliance, and therefore individual's action is of little concern for others (Bontempo, 1993; Cenkci, 2018). People of individualistic societies view interactions within relationships and groups as occurring between independent individuals, and thus, disagreements and conflicts are accepted as a natural and inevitable aspect of social life.

In contrast, employees of collectivist societies sacrifice personal goals to maximize the group's benefit; consequently, people dislike disagreements. For example, Japanese have developed social structures, institutional culture, and customs for avoiding or reducing conflicts (Ohbuchi, Fukushima, \& Tedeschi, 1999). Being collectivist, Japanese indicated a strong preference for avoiding tactics and were most concerned with maintaining social relationships and therefore preferred avoidance tactics, whereas the individualists (e.g., Americans) showed a strong use of assertive tactics in conflict situations, with a greater concern for attaining justice for themselves. Conflict resolution studies by Bresnahan, Ohashi, Liu, Nebashi, and Liao (1999) and 
Yuen (1998) revealed that Singaporeans being collectivist and hierarchical, their conflict resolution styles are very consistent with earlier studies that individuals from collectivistic societies would adopt.

Other studies investigated East-West differences by comparing U.S. managers to a matched group in an Asian society (e.g., Morris et al., 1998). The results showed that individualistic nations (US) tend to give priority to personal goals and preferences; whereas, collectivistic nations (China, Singapore) are more likely to give priority to the needs of the group (Ohbuchi \& Takahashi, 1994; Ohbuchi et al., 1999; Trubisky et al., 1991). Specifically, collectivists are likely to adopt the avoiding and obliging styles of handling conflicts that emphasize the value for passive compliance and for maintaining relational harmony in conflict situations. In contrast, individualists, associated with direct and active modes of expression, prefer the competing and dominating styles of handling conflict that emphasize the values of autonomy, competitiveness, and the need for control.

\section{Conflict Management Styles}

CMS refer to an individual's characteristic modes of managing disputes in various interaction episodes (Ting-Toomey et al., 2000). In conceptualizing CMS, Blake and Mouton (1964) introduced the dual-concern model in that an individual's preferred conflict styles depend on satisfying the other person's concerns (cooperation) on one hand, and satisfying one's own concern (assertiveness or competition) on the other hand. Based on the dual-concern model, Rahim (2001) classified CMS into five: integrating (high concern for the self and for others), compromising (moderate concern for the self and for others), obliging (low concern for the self and high concern for others), dominating (high concern for the self and low concern for others), and avoiding (low concern for the self and for others).

Trubisky et al., (1991) examined the cultural differences in conflict management between American and Taiwanese college students. The results showed that American students were less likely to use obliging and avoiding styles but more likely to use integrating and compromising styles as compared to their Taiwanese counterparts. Study by Wei, Yuen, and Zhu (2001) examined how national culture, organizational culture, and managerial factors influence managers' conflict resolution styles. The results reveal that American managers preferred dominating and integrating styles more than their Asian counterparts and that American managers were less likely to adopt avoiding style than their Chinese Singaporeans working in local companies with the Japanese managers.

Sabo's (2006) study suggests that Americans used competing style more often than West Africans, and West Africans were more likely to use collaborative style. Likewise, Su'udy's (2009) comparative study showed that Americans preferred integrating, compromising, dominating, and obliging styles significantly more than Indonesians; whereas, Indonesians preferred the avoiding style significantly more than Americans. Study by Chiu, Man, and Thayer (1998) showed that US graduate business students tended to resolve conflict in a competitive, directive, assertive, and confrontational way; whereas, Hong Kong students preferred a collaborative and harmonious way. Result of Chiu et al's study is consistent with Ting-Toomey (1994). A large-scale quantitative study by Ting-Toomey et al., (1991) examined the conflict management of people from five different cultures i.e. Japan, China, South Korea, Taiwan, and the United States. The results revealed that American participants showed a higher preference for using a dominating approach than Japanese and Korean participants. The Chinese and Taiwanese participants showed a higher preference for using obliging and avoiding approaches than American participants (Hodis, 2005).

Other studies examine the differences of handling conflict resolution by Asians. Ma’s (2007) study showed a clear preference for a compromising style by Chinese students on negotiation process and outcomes. Surprisingly, a second preferred CMS is competing, followed by avoiding and collaborating. The results of this study provide strong support for the notion that Chinese tend to use non-confrontational style to resolve conflicts. Suppiah's (2006) study examined the use of CMS by public sector managers in Malaysia. The results showed that two-thirds $(65.5 \%)$ of the managers used integrating to handle interpersonal conflicts followed by the compromising style (23.8\%). The result of Suppiah's (2006) study is in line with Abdullah's (2001) study in that Abdullah found that Malaysian managers disliked aggressive behavior, brashness, and insensitiveness. Rather, the Malaysian managers preferred more relationship based approaches. Consequently, Malaysians preferred to choose consensus and compromise than confrontation.

Three other studies (Lather, Jain, Jain, \& Vikas, 2009; Majumdar, 2015; Mohammed, Prabhakar, \& White, 2008) examined the preferred conflict resolution styles by managers in India from various public and government sectors. The results showed that the preferred conflict resolution style was accommodating and avoiding. The result also showed that least preferred CMS were competing and collaborating styles.

\section{Methods}

\section{Research Participants}

Involved in the present study were 91 local and expatriate managers. Forty-one $\left(n_{1}=41\right)$ expatriate managers came from 15 
countries that shared both individualist and collectivist cultural backgrounds (Table 1 for nationality information of expatriate managers). Fifty $\left(n_{2}=50\right)$ local managers were Hong Kong local managers. The recruitment process of identifying research participants relied on the snowball sampling method (Dornyei, 2007) whereby the research assistants and their acquaintances helped to recruit additional participants. The final sample size consisted of 50 Hong Kong local mid-to-upper level managers and 41 expatriate managers who have been working for MNCs between 5 to 15 years.

\section{Data Collection Procedures}

Both quantitative and qualitative research methods were employed. For quantitative data, Rahim's (2001), ROCI-II Forms $\mathrm{A}, \mathrm{B}$, and C survey questionnaires (Appendices 1, 2, and 3) were administered to both expatriate and local managers working in Hong Kong MNCs. The Rahim Organizational Conflict Inventory-II (ROCI-II) is a 28 -item questionnaire measuring five independent dimensions: integrating, obliging, dominating, avoiding, and compromising. To ensure the accuracy of the translation between English and Chinese versions, the translation and back-translation methods (Brislin, 1980) were used to produce the Chinese version of the questionnaire. The instrument contains Forms A, B, and C to measure how organizational members handle their conflicts with their supervisor, subordinates, and peers. Participants responded to each statement on a 5-point Likert scale. A higher score represents greater use of a conflict style.

In-depth interviews were also conducted to strengthen the

Table 1. Nationality distribution of expatriate managers

\begin{tabular}{lc}
\hline Nationality & Number \\
\hline British & 8 \\
Singaporean & 8 \\
USA & 5 \\
German & 3 \\
Japanese & 3 \\
Malaysian & 3 \\
Australian & 2 \\
Spanish & 2 \\
Canadian & 1 \\
Filipino & 1 \\
French & 1 \\
Indian & 1 \\
Indonesian & 1 \\
New Zealander & 1 \\
Pakistani & 1 \\
\hline
\end{tabular}

findings and interpretation of the questionnaire data. All of the respondents agreed to participate in the follow-up interviews. The semi-structured interview guide was used. Each interview lasted for about 30 minutes. Questions related to preferred CMS at different organizational levels. The research assistants were also trained to scrutinize the inconsistency between interviewee's elaborations and results of the questionnaire calculations.

In interviews with Hong Kong local managers, mixed codes (Cantonese and English) were used. Before conducting interviews, research assistants collected demographic data of the interviewees. Each interviewee then completed Rahim's questionnaires for the Forms A, B, and C. Upon completing the Forms, the research assistants computed the scores and found the dominant style of conflict resolution. When conducting interviews, "objectifying interviewing technique" (Redding, 1990; Sjoberg \& Nett, 1968) was adopted in that interviewers supplied background and then both parties mutually explored issues. For the present study, a similar methodology was used but one that differed is the use of individual rather than group interviews. In doing so, the interviewer first asked whether the dominant conflict resolution style as measured by the questionnaires accurately reflected the interviewee's CMS. The managers were also asked whether they would manage conflicts differently when handling conflicts with organizational members coming from similar or different cultural orientations at different organizational levels. To substantiate, managers were encouraged to give examples of conflict resolution situations.

\section{Data Analysis}

The quantitative data examines the similarities and differences of CMS between local and expatriate managers working in MNCs located in Hong Kong. To compare the differences in using five CMS, the descriptive analysis and independent sample $t$-test were employed. The study also investigates whether and how local and expatriate managers exhibited similar or different CMS when handling conflicts at different organizational levels; namely to superiors, subordinates, and peers. In doing so, an analysis of variance (ANOVA) test was conducted to compare the differences. Post hoc test was also used to further investigate the differences at the organizational levels. The qualitative interview data was transcribed and compiled. The collected qualitative data other than English were translated into English for further analysis. For this article, we report only the quantitative data.

\section{Results}

To report the findings, we first discuss the preferred CMS by local and expatriate managers as a whole. We also compare the use 
of CMS to examine whether the local and expatriate managers exhibited similar or different CMS in dealing conflicts with organizational members from different organizational levels. The extent to which cultures affect these individuals in handling conflicts differently or similarly is also addressed where applicable.

\section{Preferred Conflict Management Styles by Local and}

Expatriate Managers

RQ1 examines preferred CMS used by local and expatriate managers. To answer RQ1, we first present an overall preferred CMS by local and expatriate managers. We also compare the between-group differences by employing a sample $t$-test to examine whether there are significant differences. Figure 1 shows the preferred CMS by local and expatriate managers at different organization levels.

Figure 1(a) shows that $54 \%$ of the local managers preferred integrating when handling conflicts with their superiors while $62 \%$ of them preferred integrating in handling conflicts with subordinates, followed by $56 \%$ of them preferred integrating when handling conflicts with peers. Figure 1(b) reveals that $54 \%$ of expatriate managers preferred integrating when dealing conflicts with superiors. Expatriate managers however exhibited a slightly higher percentage in adopting integrating than the local managers when handling conflicts with subordinates $(68 \%$ versus $62 \%$ ) and with peers (63\% versus $56 \%$ ).

In comparing the remaining four preferred CMS, the results showed that compromising was the second preferred CMS by local managers when handling conflicts with subordinates (18\%) and peers (24\%). As for expatriate managers, 19\% of them preferred compromising when dealing conflicts with superiors and $17 \%$ of them would use this style when dealing with peers, but only $7 \%$ of expatriate managers would use compromising when handling conflicts with subordinates. Unlike local managers using a compromising when handling conflicts with subordinates, expatriate managers preferred dominating (17\%) when dealing conflicts with the subordinates.

For the use of avoiding style, $12 \%$ of local and expatriate managers preferred this style when handling conflicts with superiors. However, local managers were more likely than expatriate managers to use avoiding to peers (12\% vs 3\%). Another major difference between the local and expatriate managers is the use of obliging style. While $18 \%$ of local managers preferred obliging style when dealing conflicts with superiors, only $10 \%$ of the expatriate managers would use obliging, instead, these

(a) Local Managers

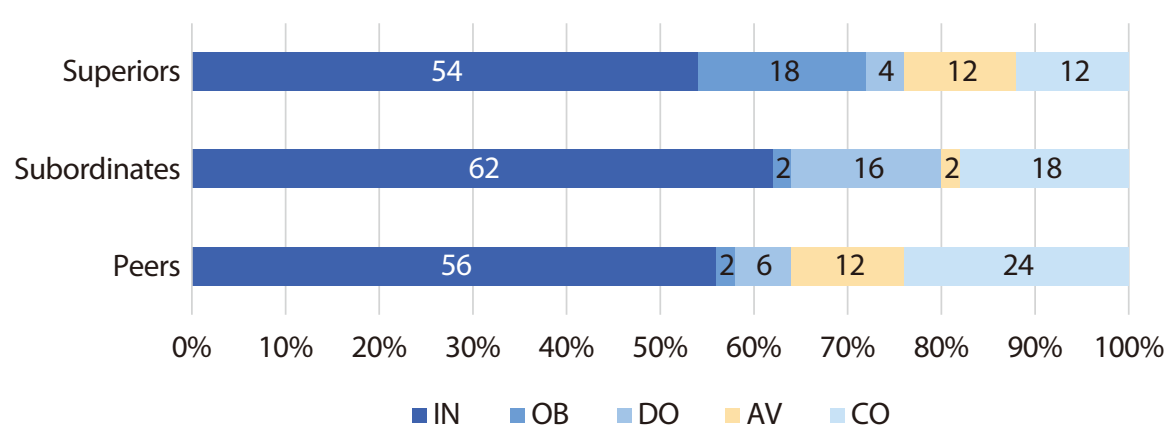

(b) Expatriate Managers

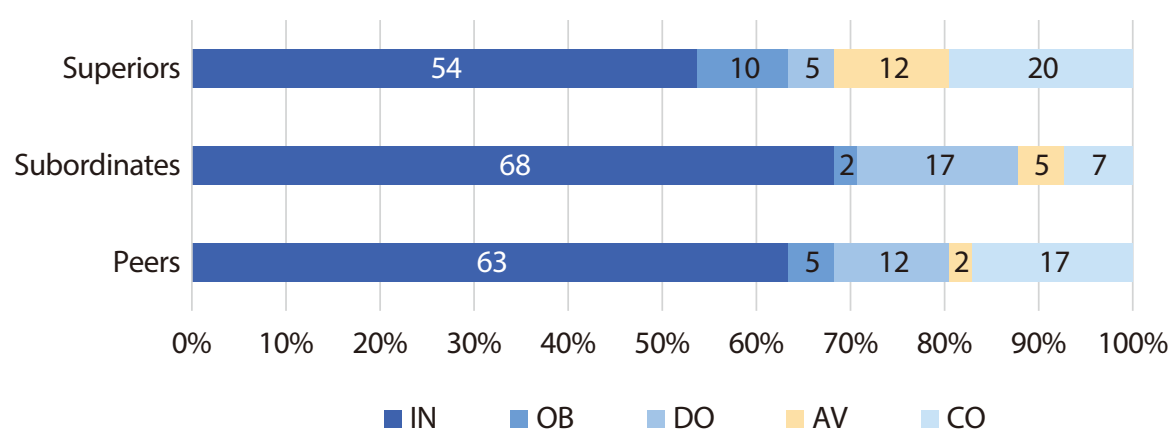

Figure 1. Preferred conflict management styles by local and expatriate managers to superiors, subordinates and peers. IN, integrating; OB, obliging; DO, dominating; AV, avoiding; CO, compromising. 
expatriate managers preferred compromising (19\%) when dealing with the conflicts with superiors.

To further examine whether there are between-group differences, a sample $t$-test was employed. Table 2 shows that local managers are more likely than expatriate managers to use dominating $(M=3.54,3.35, t=1.90, p=.06)$ and compromising $(M$ $=3.72,3.43, t=1.91, p=.06) \mathrm{CMS}$ at .10 significant level when dealing the conflicts with subordinates. Local managers are also more likely than expatriate managers to use avoiding $(M=$ $3.18,2.94, t=1.78, p=.08$ ) when handling conflicts with peers. Moreover, the significant difference was found between expatriate managers and local managers in using integrating when handling conflicts with peers $(M=4.35,4.15, t=2.11, p<.05)$ at .05 significance level.

As nearly half of the expatriate managers (18 of 41) came from collectivist cultural societies (e.g., Singapore, Malaysia), we further divide the expatriate managers into two groups: individualist group (e.g., UK, US) and collectivist group (e.g., India, Indonesia). In doing so, it allows us to examine whether differences exist between expatriate managers from collectivist societies and individualist societies. Results of the sample $t$-test did not show any significant difference between collectivist expatriate managers and individualist expatriate managers.

As there is no significant difference between the collectivist expatriate group and individualist expatriate group, we com- bined local managers with collectivist expatriate managers and made a comparison to examine whether the differences exist between managers from collectivist societies and individualist societies. The results showed that managers from collectivist cultures slightly preferred obliging CMS than the individualist managers when handling conflicts with superiors $(M=3.68$, $3.48, t=1.691, p=.095)$ at .10 significance level. The results also revealed that collectivist managers preferred avoiding than individualist managers when dealing conflicts with subordinates ( $M$ $=3.00,2.71, t=1.709, p=.091)$ and with peers $(M=3.27,2.85$, $t=1.739, p=.086)$ at .10 significance level.

\section{Preferred CMS at Different Organizational Levels by Local and Expatriate Managers}

RQ2 examines whether local and expatriate managers exhibited similar or different CMS when managing conflicts at different organizational levels: to superiors, to subordinates, and to peers? To answer RQ2, a one-way ANOVA was conducted to compare the use of five preferred CMS in handling conflicts with superiors, subordinates, and peers by local managers and expatriate managers. The results showed the significant differences among the local managers in using obliging $(F=9.115, p<.01)$, dominating $(F=4.58, p<.05)$, and compromising $(F=2.62, p<.10)$ CMS when handling conflicts at different organizational levels. The results also showed the significant differences among expa-

Table 2. A comparison of conflict management styles between expatriate and local managers

\begin{tabular}{|c|c|c|c|c|c|c|c|}
\hline \multirow[t]{2}{*}{ To } & \multirow[t]{2}{*}{ CMS } & \multicolumn{3}{|c|}{ Local vs. Expatriate } & \multicolumn{3}{|c|}{ Individualist vs. Collectivist in expatriate } \\
\hline & & $\begin{array}{l}\text { Local } \\
(n=50)\end{array}$ & $\begin{array}{l}\text { Expatriate } \\
(n=41)\end{array}$ & $t$-value & $\begin{array}{l}\text { Individualist } \\
\quad(n=23)\end{array}$ & $\begin{array}{l}\text { Collectivist } \\
(n=18)\end{array}$ & $t$-value \\
\hline \multirow[t]{5}{*}{ Superiors } & IN & 4.14 & 4.11 & 0.48 & 4.05 & 4.17 & .062 \\
\hline & $\mathrm{OB}$ & 3.72 & 3.52 & 1.17 & 3.53 & 3.51 & 1.215 \\
\hline & DO & 3.21 & 3.27 & 0.50 & 3.29 & 3.25 & .424 \\
\hline & AV & 3.23 & 2.99 & 1.08 & 2.88 & 3.10 & .106 \\
\hline & $\mathrm{CO}$ & 3.81 & 3.84 & 0.62 & 3.85 & 3.82 & .191 \\
\hline \multirow[t]{5}{*}{ Subordinates } & IN & 4.11 & 4.07 & 0.07 & 4.17 & 3.96 & .566 \\
\hline & $\mathrm{OB}$ & 3.22 & 3.16 & 0.31 & 3.29 & 3.03 & .082 \\
\hline & DO & 3.35 & 3.54 & $1.90^{* *}$ & 3.33 & 3.36 & .249 \\
\hline & $\mathrm{AV}$ & 2.83 & 3.01 & 0.97 & 2.72 & 2.95 & 1.372 \\
\hline & $\mathrm{CO}$ & 3.43 & 3.72 & $1.91^{* *}$ & 3.56 & 3.29 & .145 \\
\hline \multirow[t]{5}{*}{ Peers } & IN & 4.15 & 4.35 & $2.11^{*}$ & 4.31 & 4.40 & .572 \\
\hline & $\mathrm{OB}$ & 3.29 & 3.29 & 0.01 & 3.15 & 3.42 & .406 \\
\hline & DO & 3.16 & 3.32 & 0.56 & 3.59 & 3.07 & 1.277 \\
\hline & $\mathrm{AV}$ & 3.18 & 2.94 & $1.78^{* *}$ & 2.95 & 2.94 & .822 \\
\hline & $\mathrm{CO}$ & 3.87 & 3.73 & 0.89 & 3.79 & 3.94 & .210 \\
\hline
\end{tabular}

Note. CMS, conflict management style; IN, integrating; $\mathrm{OB}$, obliging; $\mathrm{DO}$, dominating; $\mathrm{AV}$, avoiding; $\mathrm{CO}$, compromising. ${ }^{*} p<.05 .{ }^{* *} p<.10$. 
triate managers in using integrating $(F=3.07, p<.05)$, obliging $(F=3.34, p<.05)$, and compromising $(F=4.94, p<.01)$ to handle conflicts.

We also employed a post hoc test to further examine whether both local and expatriate managers exhibited different CMS when dealing conflicts at different organizational levels. The results indicated a significant difference that local managers preferred obliging in handling conflicts with superiors $(p<$ $.001)$ and peers $(p<.01)$ than to subordinates. The results also showed that local managers preferred dominating when dealing conflicts with subordinates $(p<.05)$ at .05 significance level, and use compromising when dealing conflicts with superiors $(x=$ $3.91,3.71, p=.093)$ at .10 significant level than to subordinates and peers. Taken together, these results suggest that local managers preferred obliging when handling conflicts with superiors and peers, dominating to subordinates, and compromising to superiors.

Results of the post hoc test revealed that expatriate managers preferred obliging when handling conflicts with superiors $(p<$ $.05)$, but no difference was found when handling conflicts with subordinates and peers. No significant difference was found for the use of dominating and avoiding in handling conflicts at the three organizational levels. Expatriate managers however preferred compromising when handling conflicts with superiors $(p<.05)$ and with peers $(p<.05)$ at .05 significance level. These results suggest that expatriate managers preferred obliging when handling conflicts with superiors, and compromising was the preferred CMS when handling conflicts with superiors and peers.

\section{Discussion}

We posed two RQs and found that integrating was the most preferred CMS by local and expatriate managers at three organizational levels (superiors, subordinates, and peers). Obliging and compromising were the second most preferred CMS by local managers in that obliging was preferred when handling conflicts with superiors, and compromising was preferred when handling conflicts with subordinates and peers. Compromising was also the second most preferred by expatriate managers when they handled conflicts with superiors and peers. When handling conflicts with subordinates, both local and expatriate managers preferred dominating. Avoiding was used by local managers when handling conflicts with superiors and peers, but not to subordinates. Similarly, expatriate managers preferred avoiding when handling conflicts with superiors, but not to subordinates and peers.

Results of the $t$-test revealed a significant difference between local and expatriate managers about the use of integrating at the .05 significance level, and the use of dominating and compromising at the 10 significant level. Reason for such an insignificant difference between the expatriate and local managers can be speculated in two possibilities. First, Hong Kong being British colony for almost a century, Hong Kong local managers may have been assimilated to the individualistic culture, although Hong Kong was categorized as collectivist by Hofstede (1980, 1991). Second, Hong Kong local managers in the present study have been working for the MNCs for an average of ten years; therefore, the individualistic corporate culture may have influenced their way of handling conflicts. Nevertheless, being collectivist, the local managers felt that they were obliged to conform to the decisions made by the superiors for the sake of harmony and face saving.

Our findings of the RQ2 reveal the significant differences in using obliging, dominating and compromising among local managers when handling conflicts at different organizational levels. Significant differences are also found among expatriate managers in using integrating, obliging, and compromising at different organizational levels. A post hoc test was also conducted and the results indicated that obliging and compromising were preferred by local managers when handling conflicts with superiors and peers and that dominating was preferred when handling conflicts with subordinates. As for expatriate managers, results of the post hoc test indicated that obliging was preferred when handling conflicts with superiors and that compromising was preferred when handling conflicts with superior and peers.

Taken together with these results, the present study reveals the prevalence of integrating CMS in the modern workplace. The findings also reflect the impact of the culture on superior and subordinate relationships and the use of obliging when handling conflicts with superiors.

\section{The Prevalence of Integrating Style in Modern Workplace}

The present study partially confirms findings of the previous research. The findings differ from the previous studies suggesting that integrating style is likely to be the most widely practiced CMS in the modern workplace. Regardless of cultural backgrounds, more than half of participants preferred integrating at different organizational levels as shown in Figure 1. Because of its win-win solution to the conflicts, integrating style has become the most valued merit in modern management science. As noted, conflicts should not be seen as a "wasteful outbreak of incompatibilities, but a normal process whereby socially valuable differences register themselves for the enrichment for all concerned". Under this principle, integrating style which con- 
cerns the best interest of both parties becomes popular in the modern workplace.

Due to its promising outcome, participants tended to perceive that they used integrating to solve the conflicts even if they didn't. From the transcripts of the interview data, it is interesting to notice that a great number of interviewees, especially expatriate managers, assumed that they used integrating to resolve the conflicts even before they knew their results. However, when the interviewees were asked to provide examples to elaborate the concept, the interviewers realized that some of the interviewees confused the integrating style with the compromising style. For example, when the interviewees gave examples of integrating, they started describing how they negotiated and bargained with counterparts to reach a middle ground. Their illustrations fit under the compromising style which emphasizes yielding to something so as to gain benefits when dealing with the conflicts. Such misunderstanding may have contributed to the large percentage of integrating style in the final result. Despite this, integrating is still the most preferred CMS simply because it satisfies both parties to achieve win-win situations.

\section{Win-Lose Orientation and Relationship at Different Organizational Levels}

In most cases, compromising is the second preferred CMS following the integrating style. Such a result makes sense because most interviewees preferred a partial win/partial loss than a zero-sum situation. However, a distinct difference between local and expatriate managers in using compromising style is that local managers were more inclined to adopt compromising when handling conflicts with the subordinates and peers while expatriate managers adopted this style when handling conflicts with superiors and peers.

In comparing the use of dominating and compromising styles between local and expatriate managers, an interesting difference is observed that expatriate managers preferred dominating and compromising to handle the conflicts, but no difference was observed by local managers. The result shows that while $17 \%$ of expatriate managers were likely to use dominating style, only $7 \%$ of them adopted compromising when dealing conflicts with the subordinates. As for local managers, $16 \%$ of them preferred dominating while $18 \%$ chose to use compromising when handling conflicts with subordinates. These results suggest that when handling conflicts with subordinates, no difference was observed between both local and expatriate managers in the use of dominating style ( $16 \%$ versus $17 \%$ ); whereas, local managers were more likely to adopt compromising than expatriate managers (18\% versus $7 \%)$ in using compromising to handle the conflicts with the subordinates.
Differences in Using Obliging Style between Local and Expatriate Managers

Number of local managers (9 of 50) using an obliging style to superiors is notably higher than that of expatriate managers (4 of 41). As obliging style is a reflection of low concern for self and high concern for the other party involved, the result suggests that the collectivist local managers were more willing to yield their own viewpoints to solve the conflicts with their superiors. When compared with individualist cultures, individuals from collectivist societies value within-group harmony. To maintain a united working environment, personal viewpoints or so-called "individualistic heroism" is not encouraged. This concept can be evidenced by interviewees' remarks that "subordinates should always follow what the superior says or wants even though we may disagree with superior's views." The local managers thought that the superior is the one who shall hold responsibility to the group and the decisions they make. To the collectivist local managers, superiors can best represent the group, so they tend to give priority to the will of superiors before expressing their own views or ideas.

The power distance is another culture element that may contribute to the difference. Asian culture is categorized as high power distance by Hofstede $(1985,1991)$, which means that the power difference between subordinates and superiors tend to be larger than that of Western cultures. To local managers, the superiors possess the authority, and therefore, the superiors should be the decision makers. In contrast, in Western individualist cultures where the power distance is low, superiors and subordinates are treated as equal individuals, and therefore, the unequal superior-subordinate relationship is weak. Because of this, the disagreement between the superior and the subordinate can be discussed and negotiated. Consequently, local managers intended to use obliging style when handling conflicts with superiors, while expatriate managers do not have a special tendency in using obliging style to superiors.

\section{Implications and Limitations}

Present study contributes to the body of literature on the preferred CMS between collectivist and individualist societies in three ways. First, it extends empirical research in using student samples to real-world business professionals in a multinational context. Specifically, the study examines whether local managers and expatriate managers adopted different CMS when handling conflicts at different organizational levels (superiors, subordinates, and peers). Second, the study contributes empirical quantitative data to the body of research knowledge about preferred CMS among collectivist local managers and expatriate managers from individualist and collectivist cultural societies. 
Third, the study focuses on comparing preferred CMS between local and expatriate managers at different organizational levels, which means that the findings have relevance for Asian-based or Western-based MNCs in selecting candidates working for the organizations.

\section{Limitations and Suggestions for Future Research}

Although the study has revealed important findings, yet the results should be interpreted with caution due to its limitations. The first limitation is the use of self-reported survey questionnaires. The use of self-reported questionnaires may increase the occurrence of response bias. Although self-reported CMS may not correspond to actual behavior, it allowed us to compare results of the present study with previous findings. Future studies would benefit from multiple methodologies including other qualitative methodologies, such as simulated incident analyses in addition to interviews in studying CMS across cultures.

The second limitation is the sample size. Although 273 questionnaires were collected from 50 local and 41 expatriate managers, the differences in sample size between managers from individualist and collectivist cultural backgrounds are 1 to 3 . Although the number of local and expatriate managers is nearly equal (50 to 41), half of the expatriate managers shared the collectivist cultural background which is similar to the collectivist local managers. In this connection, using a multiple-sample from different populations, especially the working population from different cultural backgrounds would provide greater insight, and therefore, findings could be more generalizable.

In all, future studies would benefit from this line of research by examining the relationship between I-C facets when the subjects are dealing with in-group, out-group as well as interpersonal and inter-group conflict situations. Future research should also examine CMS beyond the dichotomy of "concern for self" and "concern for other" and further explore the cultural context of the compromising management style.

\section{Conclusion}

The present study investigates how and whether Hong Kong local managers (collectivist) and expatriate managers (collectivist and individualist) exhibited similar or different CMS when dealing conflicts with superiors, subordinates, and peers. The findings reveal similar and different CMS that are found in local and expatriate managers and that culture can be a determining factor affecting the choice of CMS between managers from different culture orientations and at different organizational hierarchies.

Of the five CMS, results show that integrating is most pre- ferred, with compromising and obliging came as the second most preferred at different organizational levels. Dominating was preferred only when handling conflicts with the subordinates. Avoiding was the least preferred CMS by both local and expatriate managers.

Teamwork is very common in modern workplace regardless of cultures. With a common goal in mind, organizational members are more willing to respect each other's opinions; consequently, they would place more or less the same level of concern for self and the other party involved, and thereby work out a decision acceptable to both parties when conflict occurs. Therefore, integrating and compromising styles were preferred by the participants. Being influenced by collectivist cultural orientation, harmony and power distance are valued in the organization; consequently, obliging is more likely to be preferred by collectivist local managers than expatriate managers, and dominating style is only used when handling conflicts with subordinates, not to superiors and peers. In the business world, the major aim is to solve problems and get tasks done. Therefore, avoiding is the least preferred CMS because negative effects may be brought to teamwork and productivity when one party involved in the conflict is always ignored, or when the conflict goes unaddressed.

\section{References}

Abdullah, S. H. (2001). Managing in the Malaysian context. In Management in Malaysia (pp. 51-72). Kuala Lumpur, Malaysia: Malaysian Institute of Management.

Aguinis, H., \& Kraiger, K. (1996). Intervening in emerging markets: Back to the basics, or go home empty-handed. The Industrial-Organizational Psychologist, 33(3), 84-87.

Blake, R. R., \& Mouton, J. S. (1964). The managerial grid. Houston, TX: Gulf.

Bontempo, R. (1993). Translation fidelity of psychological scales: An item response theory analysis of an individualism-collectivism scale. Journal of Cross-Cultural Psychology, 24(2), 149-166.

Bresnahan, M. J., Ohashi, R., Liu, W. Y., Nebashi, R., \& Liao, C. C. (1999). A comparison of response styles in Singapore and Taiwan. Journal of Cross-Cultural Psychology, 30(3), 342-358.

Brislin, R. W. (1980). Translation and content analysis of oral and written materials. In H. C. Triandis, \& J. W. Berry (Eds.), Handbook of cross-cultural psychology (Vol. 1, pp. 389-444). Boston, MA: Allyn \& Bacon.

Cenkci, A. T. (2018). Leader power, conflict handling styles, and subordinate compliance: A study on information technology professionals in Turkey. International Journal of Management and Economics, 54(1), 18-35. 
Chen, G. M., \& Starosta, W. J. (1998). Foundations of intercultural communication. Needham Heights, MA: Allyn \& Bacon.

Chiu, R. K., Man, J. S. W., \& Thayer, J. (1998). Effects of role conflicts and role satisfactions on stress of three professions in Hong Kong: A path analysis approach. Journal of Managerial Psychology, 13(5/6), 318-333.

Desikan, A. (2018, April 28). Managers spend about 40\% of time resolving employee conflict. The Times of India. Retrieved from https://timesofindia.indiatimes.com/business/india-business/ managers-spend-about-40-of-time-resolving-employee-conflictsat-work/articleshow/63947249.cms

Dornyei, Z. (2007). Research methods in applied linguistics. New York, NY: Oxford University Press.

Gudykunst, W. B. (1994). Bridging differences: Effective intergroup communication. Thousand Oaks, CA: Sage.

Hall, E. T. (1976). Beyond culture. Garden City, NY: Doubleday Anchor Books.

Hodis, G. M. (2005). Managing intercultural conflict (Unpublished master's thesis). Southern Illinois University, Carbondale, IL.

Hofstede, G. (1980). Culture’s consequences: International differences in work-related values. Beverly Hills, CA: Sage.

Hofstede, G. (1985). The interaction between national and organizational value systems. Journal of Management Studies, 22(4), 347-357.

Hofstede, G. (1991). Cultures and organizations: Software of the mind: Intercultural cooperation and its importance for survival. Maidenhead, UK: McGraw-Hill.

Lather, A. S., Jain, V. K., Jain, S., \& Vikas, S. (2009). A study of conflict resolution modes adopted in Delhi Development Authority (DDA) and Delhi Jal Board (DJB). JK Journal of Management and Technology, 8, 119-133.

Leung, K. (1988). Some determinants of conflict avoidance. Journal of Cross-Cultural Psychology, 19(1), 125-136.

Ma, Z. (2007). Chinese conflict management styles and negotiation behaviours: An empirical test. International Journal of Cross Cultural Management, 7(1), 101-119.

Majumdar, M. (2015). The ASEAN way of conflict management in the South China Sea. Strategic Analysis, 39(1), 73-87.

Mohammed, U. K., Prabhakar, G. P., \& White, G. R. T. (2008). Culture and conflict management style of international project managers. International Journal of Business and Management, 3(5), 3-11.

Morris, M. W., Williams, K. Y., Leung, K., Larrick, R., Mendoza, M. T., Bhatnagar, D., ... Hu, J. C. (1998). Conflict management style: Accounting for cross-national differences. Journal of International Business Studies, 29(4), 729-748.

Ohbuchi, K. I., Fukushima, O., \& Tedeschi, J. T. (1999). Cultural values in conflict management: Goal orientation, goal attain- ment, and tactical decision. Journal of Cross-Cultural Psychology, 30(1), 51-71.

Ohbuchi, K. I., \& Takahashi, Y. (1994). Cultural styles of conflict management in Japanese and Americans: Passivity, covertness, and effectiveness of strategies. Journal of Applied Social Psychology, 24(15), 1345-1366.

Rahim, M. A. (2001). Managing conflict in organizations (3rd ed.). Westport, CT: Quorum Books.

Redding, S. G. (1990). The spirit of Chinese capitalism. New York, NY: Walter de Gruyter.

Sabo, C. (2006). Cultural influences on conflict management styles between West Africans and Americans (Unpublished doctoral dissertation). University of Denver, Denver, CO.

Sjoberg, G., \& Nett, R. (1968). A methodology for social research. New York, NY: Harper and Row.

Smith, P. B., \& Bond, M. H. (1993). Social psychology across cultures: Analysis and perspectives. Boston, MA: Allyn \& Bacon.

Suppiah, W. R. R. V. (2006). Conflict management styles among public sector managers in Malaysia (Unpublished doctoral dissertation). University Putra Malaysia, Serdang, Malaysia.

Su'udy, R. (2009). Conflict management styles of Americans and Indonesians: Exploring the effects of gender and collectivism/individualism (Unpublished master's thesis). University of Kansas, Lawrence, KS.

Thomas, K. W., \& Schmidt, W. H. (1976). A survey of managerial interests with respect to conflict. Academy of Management Journal, 19(2), 315-318.

Ting-Toomey, S. (1985). Toward a theory of conflict and culture. In W. B. Gudykunst, L. Stewart, \& S. Ting-Toomey (Eds.), Communication, culture, and organizational processes: International and intercultural communication annual (Vol. 9, pp. 71-86). Beverly Hills, CA: Sage.

Ting-Toomey, S. (1988). Intercultural conflict styles: A face-negotiation theory. In Y. Kim, \& W. Gudykunst (Eds.), Theories in intercultural communication (pp. 213-235). Newbury Park, CA: Sage.

Ting-Toomey, S. (1994). SUNY series in human communication processes. In S. Ting-Toomy (Ed.), The challenge of facework: Cross-cultural and interpersonal issues. New York, NY: State University of New York Press.

Ting-Toomey, S., Gao, G., Trubisky, P., Yang, Z., Kim, H. S., Lin, S. L., \& Nishida, T. (1991). Culture, face maintenance, and styles of handling interpersonal conflict: A study in five cultures. International Journal of Conflict Management, 2(4), 275-296.

Ting-Toomey, S., Yee-Jung, K. K., Shapiro, R. B., Garcia, W., Wright, T. J., \& Oetzel, J. G. (2000). Ethnic/cultural identity salience and conflict styles in four US ethnic groups. International Journal of Intercultural Relations, 24(1), 47-81. 
Trubisky, P., Ting-Toomey, S., \& Lin, S. L. (1991). The influence of individualism-collectivism and self-monitoring on conflict styles. International Journal of Intercultural Relations, 15(1), 65-84.

Yuen, C. C. (1998). Social-cultural context of perceptions and approaches to conflict: The case of Singapore. In K. Leung, \& D. Tjosvold (Eds.), Conflict management in the Asia Pacific: Assumptions and approaches in diverse cultures (pp. 123-145). Singapore: John Wiley \& Sons.
Wei, W., Yuen, E., \& Zhu, J. J. (2001, February). Individualism-collectivism and conflict resolution styles: A cross study of managers in Singapore. Retrieved from https://www.adr.gov/ events/2009/nov19-2009-materials-article.pdf

Weider-Hatfield, D. (1988). Assessing the Rahim organizational conflict inventory-II (ROCI-II). Management Communication Quarterly, 1(3), 350-366. 


\section{Appendix}

Appendix 1. Superiors

\section{ROCI-II, Form A}

Confidential

You may have incompatibilities, disagreements, or differences (i.e., conflict) with your supervisor. Circle a number on the scale provided after each statement, to indicate how you handle your conflict with your supervisor. Try to recall as many recent conflict situations as possible in ranking these statements.

Scale: $5=$ Strongly Agree, $4=$ Agree, $3=$ Undecided, $2=$ Disagree, $1=$ Strongly Disagree

1 I try to investigate an issue with my supervisor to find a solution acceptable to us.

2 I generally try to satisfy the needs of my supervisor.

3 I attempt to avoid being "put on the spot" and try to keep my conflict with my supervisor to myself.

4 I try to integrate my ideas with those of my supervisor to come up with a decision jointly.

5 I try to work with my supervisor to find solution to a problem which satisfy our expectations.

6 I usually avoid open discussion of my differences with my supervisor.

7 I try to find a middle course to resolve an impasse.

8 I use my influence to get my ideas accepted.

9 I use my authority to make a decision in my favor.

10 I usually accommodate the wishes of my supervisor.

11 I give in to the wishes of my supervisor.

12 I exchange accurate information with my supervisor to solve a problem together.

13 I usually allow concessions to my supervisor.

14 I usually propose a middle ground for breaking deadlocks.

15 I negotiate with my supervisor so that a compromise can be reached.

16 I try to stay away from disagreement with my supervisor.

17 I avoid an encounter with my supervisor.

18 I use my expertise to make a decision in my favor.

19 I often go along with the suggestions of my supervisor.

20 I use "give and take" so that a compromise can be made.

21 I am generally firm in pursuing my side of the issue.

22 I try to bring all our concerns out in the open so that the issues can be resolved in the best possible way.

23 I collaborate with my supervisor to come up with decisions acceptable to us.

24 I try to satisfy the expectations of my supervisor.

25 I sometimes use my power to win a competitive situation.

26 I try to keep my disagreement with my supervisor to myself in order to avoid hard feelings.

27 I try to avoid unpleasant exchanges with my supervisor.

28 I try to work with my supervisor for a proper understanding of a problem.

\begin{tabular}{|c|c|c|c|c|}
\hline 5 & 4 & 3 & 2 & 1 \\
\hline 5 & 4 & 3 & 2 & 1 \\
\hline 5 & 4 & 3 & 2 & 1 \\
\hline 5 & 4 & 3 & 2 & 1 \\
\hline 5 & 4 & 3 & 2 & 1 \\
\hline 5 & 4 & 3 & 2 & 1 \\
\hline 5 & 4 & 3 & 2 & 1 \\
\hline 5 & 4 & 3 & 2 & 1 \\
\hline 5 & 4 & 3 & 2 & 1 \\
\hline 5 & 4 & 3 & 2 & 1 \\
\hline 5 & 4 & 3 & 2 & 1 \\
\hline 5 & 4 & 3 & 2 & 1 \\
\hline 5 & 4 & 3 & 2 & 1 \\
\hline 5 & 4 & 3 & 2 & 1 \\
\hline 5 & 4 & 3 & 2 & 1 \\
\hline 5 & 4 & 3 & 2 & 1 \\
\hline 5 & 4 & 3 & 2 & 1 \\
\hline 5 & 4 & 3 & 2 & 1 \\
\hline 5 & 4 & 3 & 2 & 1 \\
\hline 5 & 4 & 3 & 2 & 1 \\
\hline 5 & 4 & 3 & 2 & 1 \\
\hline 5 & 4 & 3 & 2 & 1 \\
\hline 5 & 4 & 3 & 2 & 1 \\
\hline 5 & 4 & 3 & 2 & 1 \\
\hline 5 & 4 & 3 & 2 & 1 \\
\hline 5 & 4 & 3 & 2 & 1 \\
\hline 5 & 4 & 3 & 2 & 1 \\
\hline 5 & 4 & 3 & 2 & 1 \\
\hline
\end{tabular}




\title{
ROCI-II, Form B
}

\author{
Confidential
}

You may have incompatibilities, disagreements, or differences (i.e., conflict) with your subordinates. Rank each of the following statements, by circling a number on the scale provided after each statement, to indicate how you handle your conflict with your subordinates. Try to recall as many recent conflict situations as possible in ranking these statements.

Scale: $5=$ Strongly Agree, $4=$ Agree, $3=$ Undecided, $2=$ Disagree, $1=$ Strongly Disagree

1 I try to investigate an issue with my subordinates to find a solution acceptable to us.

2 I generally try to satisfy the needs of my subordinates.

3 I attempt to avoid being "put on the spot" and try to keep my conflict with my subordinates to myself.

4 I try to integrate my ideas with those of my subordinates to come up with a decision jointly.

5 I try to work with my subordinates to find solution to a problem which satisfy our expectations.

6 I usually avoid open discussion of my differences with my subordinates.

7 I try to find a middle course to resolve an impasse.

8 I use my influence to get my ideas accepted.

9 I use my authority to make a decision in my favor.

10 I usually accommodate the wishes of my subordinates.

11 I give in to the wishes of my subordinates.

12 I exchange accurate information with my subordinates to solve a problem together.

13 I usually allow concessions to my subordinates.

14 I usually propose a middle ground for breaking deadlocks.

15 I negotiate with my subordinates so that a compromise can be reached.

16 I try to stay away from disagreement with my subordinates.

17 I avoid an encounter with my subordinates.

18 I use my expertise to make a decision in my favor.

19 I often go along with the suggestions of my subordinates.

20 I use "give and take" so that a compromise can be made.

21 I am generally firm in pursuing my side of the issue.

22 I try to bring all our concerns out in the open so that the issues can be resolved in the best possible way.

23 I collaborate with my subordinates to come up with decisions acceptable to us.

24 I try to satisfy the expectations of my subordinates.

25 I sometimes use my power to win a competitive situation.

26 I try to keep my disagreement with my subordinates to myself in order to avoid hard feelings.

27 I try to avoid unpleasant exchanges with my subordinates.

28 I try to work with my subordinates for a proper understanding of a problem.

\begin{tabular}{|c|c|c|c|c|}
\hline 5 & 4 & 3 & 2 & 1 \\
\hline 5 & 4 & 3 & 2 & 1 \\
\hline 5 & 4 & 3 & 2 & 1 \\
\hline 5 & 4 & 3 & 2 & 1 \\
\hline 5 & 4 & 3 & 2 & 1 \\
\hline 5 & 4 & 3 & 2 & 1 \\
\hline 5 & 4 & 3 & 2 & 1 \\
\hline 5 & 4 & 3 & 2 & 1 \\
\hline 5 & 4 & 3 & 2 & 1 \\
\hline 5 & 4 & 3 & 2 & 1 \\
\hline 5 & 4 & 3 & 2 & 1 \\
\hline 5 & 4 & 3 & 2 & 1 \\
\hline 5 & 4 & 3 & 2 & 1 \\
\hline 5 & 4 & 3 & 2 & 1 \\
\hline 5 & 4 & 3 & 2 & 1 \\
\hline 5 & 4 & 3 & 2 & 1 \\
\hline 5 & 4 & 3 & 2 & 1 \\
\hline 5 & 4 & 3 & 2 & 1 \\
\hline 5 & 4 & 3 & 2 & 1 \\
\hline 5 & 4 & 3 & 2 & 1 \\
\hline 5 & 4 & 3 & 2 & 1 \\
\hline 5 & 4 & 3 & 2 & 1 \\
\hline 5 & 4 & 3 & 2 & 1 \\
\hline 5 & 4 & 3 & 2 & 1 \\
\hline 5 & 4 & 3 & 2 & 1 \\
\hline 5 & 4 & 3 & 2 & 1 \\
\hline 5 & 4 & 3 & 2 & 1 \\
\hline 5 & 4 & 3 & 2 & 1 \\
\hline
\end{tabular}




\title{
ROCI-II, Form C
}

\author{
Confidential
}

You may have incompatibilities, disagreements, or differences (i.e., conflict) with your peers. Please circle a number on the scale provided after each statement, to indicate how you handle your conflict with your peers. Try to recall as many recent conflict situations as possible in ranking these statements.

Scale: $5=$ Strongly Agree, $4=$ Agree, $3=$ Undecided, $2=$ Disagree, $1=$ Strongly Disagree

1 I try to investigate an issue with my peers to find a solution acceptable to us.

2 I generally try to satisfy the needs of my peers.

3 I attempt to avoid being "put on the spot" and try to keep my conflict with my peers to myself.

4 I try to integrate my ideas with those of my peers to come up with a decision jointly.

5 I try to work with my peers to find solution to a problem which satisfy our expectations.

6 I usually avoid open discussion of my differences with my peers.

7 I try to find a middle course to resolve an impasse.

8 I use my influence to get my ideas accepted.

9 I use my authority to make a decision in my favor.

10 I usually accommodate the wishes of my peers.

11 I give in to the wishes of my peers.

12 I exchange accurate information with my peers to solve a problem together.

13 I usually allow concessions to my peers.

14 I usually propose a middle ground for breaking deadlocks.

15 I negotiate with my peers so that a compromise can be reached.

16 I try to stay away from disagreement with my peers.

17 I avoid an encounter with my peers.

18 I use my expertise to make a decision in my favor.

19 I often go along with the suggestions of my peers.

20 I use "give and take" so that a compromise can be made.

21 I am generally firm in pursuing my side of the issue.

22 I try to bring all our concerns out in the open so that the issues can be resolved in the best possible way.

23 I collaborate with my peers to come up with decisions acceptable to us.

24 I try to satisfy the expectations of my peers.

25 I sometimes use my power to win a competitive situation.

26 I try to keep my disagreement with my peers to myself in order to avoid hard feelings.

27 I try to avoid unpleasant exchanges with my peers.

28 I try to work with my peers for a proper understanding of a problem.

\begin{tabular}{|c|c|c|c|}
\hline 5 & 4 & 3 & 2 \\
\hline 5 & 4 & 3 & 2 \\
\hline 5 & 4 & 3 & 2 \\
\hline 5 & 4 & 3 & 2 \\
\hline 5 & 4 & 3 & 2 \\
\hline 5 & 4 & 3 & 2 \\
\hline 5 & 4 & 3 & 2 \\
\hline 5 & 4 & 3 & 2 \\
\hline 5 & 4 & 3 & 2 \\
\hline 5 & 4 & 3 & 2 \\
\hline 5 & 4 & 3 & 2 \\
\hline 5 & 4 & 3 & 2 \\
\hline 5 & 4 & 3 & 2 \\
\hline 5 & 4 & 3 & 2 \\
\hline 5 & 4 & 3 & 2 \\
\hline 5 & 4 & 3 & 2 \\
\hline 5 & 4 & 3 & 2 \\
\hline 5 & 4 & 3 & 2 \\
\hline 5 & 4 & 3 & 2 \\
\hline 5 & 4 & 3 & 2 \\
\hline 5 & 4 & 3 & 2 \\
\hline 5 & 4 & 3 & 2 \\
\hline 5 & 4 & 3 & 2 \\
\hline 5 & 4 & 3 & 2 \\
\hline 5 & 4 & 3 & 2 \\
\hline 5 & 4 & 3 & 2 \\
\hline 5 & 4 & 3 & 2 \\
\hline 5 & 4 & 3 & 2 \\
\hline
\end{tabular}

